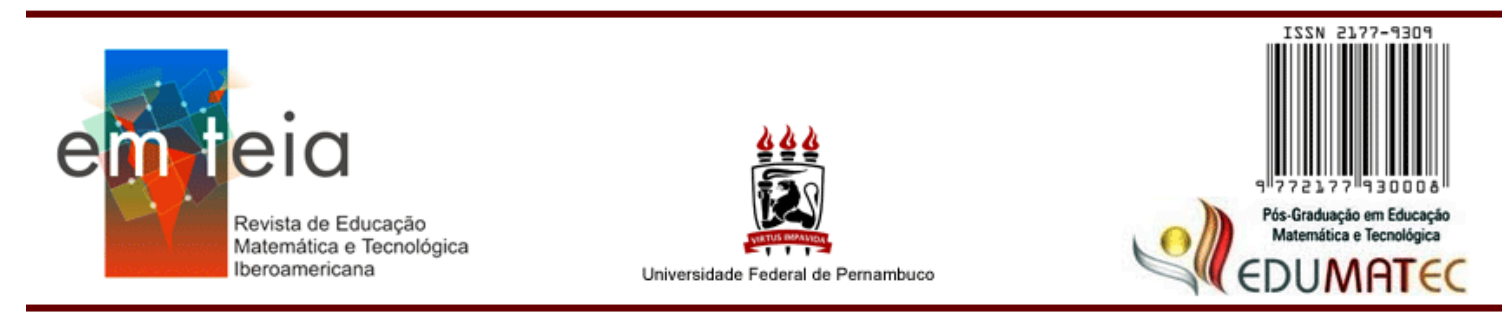

\title{
AMBIENTES VIRTUAIS DE APRENDIZAGEM: \\ a contribuição da Educação a Distância para o ensino remoto de emergência em tempos de pandemia
}

\author{
Virtual Learning Environments: \\ the contribution of Distance Education to remote emergency teaching in times of \\ pandemic
}

Taissa Vieira Lozano Burci

Doutora em Educação Universidade Estadual de Maringá e Faculdade Astorga taissalozano@gmail.com

Ana Paula de Souza Santos

Mestranda em Educação

Universidade Estadual de Maringá

contato.profanapaula@gmail.com

Patricia Lakchmi Leite Mertzig Mestre em Educação Universidade do Oeste Paulista patriciamertzig@gmail.com

\author{
Camila Tecla Mortean Mendonça \\ Doutoranda em Educação \\ Universidade Estadual de Maringá \\ Centro Universitário Cesumar \\ teclacamila@hotmail.com
}

\section{Resumo}

O presente artigo emerge em um contexto de pandemia causado pela Covid-19 que alterou totalmente a oferta da educação presencial. Dessa forma, o objetivo deste texto é explorar o uso dos Ambientes Virtuais de Aprendizagem (AVA), oriundos da Educação a Distância (EaD), como um importante recurso organizacional do ensino remoto de emergência. Acreditamos que o processo de consolidação da $\mathrm{EaD}$ e seus recursos contribui com a instrumentalização da demanda emergencial que estamos vivenciando. A metodologia adotada é uma pesquisa bibliográfica e documental com abordagem qualitativa. Observamos que o AVA foi utilizado como uma forma de organizar as aulas presenciais transpondo sua organização para um espaço virtual, em que os alunos tiveram acesso aos materiais pedagógicos da disciplina, as atividades, aos recados e aos fóruns de discussões. Concluímos que a utilização dos Ambientes Virtuais de Aprendizagem possibilitou uma melhor organização das aulas e do atendimento educacional, permitindo que os alunos pudessem acompanhar diariamente as aulas, da educação básica ao ensino superior; por outro lado, possibilitou a interação pedagógica entre os alunos e professores. Aos responsáveis pelos alunos em idade escolar, facilitou a organização da rotina escolar 
que ocorria paralelamente às suas ocupações profissionais e familiares que também foram alteradas durante a pandemia.

Palavras-chave: Ferramentas Interativas, Educação a Distância, Ensino Remoto de Emergência, Educação Presencial.

\begin{abstract}
This article emerges in a context of a pandemic caused by Covid-19 that totally altered the offer of faceto-face education. Thus, the purpose of this text is to explore the use of Virtual Learning Environments (VLE), originating from Distance Education (DE), as an important organizational resource for remote emergency teaching. We believe that the process of consolidating DE and its resources contributes to the instrumentalization of the emergency demand that we are experiencing. The adopted methodology is an exploratory bibliographic and documentary with a qualitative approach. We note that the VLE was used as a way of organizing the face-to-face classes, transposing their organization to a virtual space, in which students had access to the discipline's pedagogical materials, activities, messages and discussion forums. We concluded that the use of Virtual Learning Environments enabled a better organization of classes and educational assistance and it allowed students to follow daily classes from basic education to higher education, on the other hand, it enabled pedagogical interaction between students and teachers. The responsible of school-age students facilitated the organization of the school routine that occurred in parallel with their professional and family occupations, which were also changed during the pandemic.
\end{abstract}

Keywords: Interactive Tools, Distance Education, Emergency Remote Teaching, Face-to-face education.

\title{
Introdução
}

A pandemia do novo coronavírus, denominada Covid-19, alterou a vida das pessoas mundialmente impondo medidas de isolamento social para seu controle. Diante dessa situação, uma gama de estruturas sociais suspendeu seus atendimentos presenciais. Assim, o ano de 2020 foi marcado pela necessidade de reinvenção e adaptação de diversos setores da sociedade.

É o caso da Educação, que, na impossibilidade da promoção de encontros presenciais, precisou encontrar formas de oportunizar a continuidade dos processos de ensino e de aprendizagem para além da sala de aula. Neste sentido, a implantação de um ensino remoto, em regime de emergência, foi necessária.

Nesse contexto, no Brasil, foi promulgada a lei ${ }^{0}$ 13.979, em 6 de fevereiro de 2020, dispondo sobre "as medidas para enfrentamento da emergência de saúde pública de importância internacional decorrente do Coronavírus" (BRASIL, 2020a). No que tange o ensino superior, foram publicadas as portarias n 343 e n ${ }^{\circ} 345$, em março de 2020, pelo Ministério da Educação, autorizando as aulas remotas de emergência (BRASIL, 2020b, 2020c). Nesse formato e em substituição às aulas presenciais, foram aceitas as Tecnologias de Informação e Comunicação (TICs). 
Em 28 de abril de 2020, no âmbito do Conselho Pleno e do Conselho Nacional de Educação, foi publicado o parecer CNE/CP n $5 / 2020$, que versou sobre a "reorganização do calendário escolar e da possibilidade de cômputo de atividades não presenciais para fins de cumprimento da carga horária mínima anual, em razão da Pandemia da Covid-19” (BRASIL, 2020d).

O parecer $\mathrm{CNE} / \mathrm{CP}$ n $^{\circ}$ 5/2020 destaca a importância da reorganização dos calendários escolares, respeitando as especificidades de cada município e estado frente às condições concretas em relação à Covid-19. No entanto, salienta que essa reorganização precisa "[...] considerar propostas que não aumentem a desigualdade ao mesmo tempo em que utilizem a oportunidade trazida por novas Tecnologias Digitais de Informação e Comunicação para criar formas de diminuição das desigualdades de aprendizado" (BRASIL, 2020d, p. 3).

As Tecnologias Digitais de Informação e Comunicação (TDICs) são destacadas, nesse momento de pandemia, como uma das soluções para que o atendimento educacional continue sendo garantido no formato de ensino remoto de emergência. De forma especial, o parecer destaca as possíveis formas de atendimento, especialmente no que se refere ao uso das TDICs:

Cabe salientar que a realização das atividades pedagógicas não presenciais não se caracteriza pela mera substituição das aulas presenciais e sim pelo uso de práticas pedagógicas mediadas ou não por tecnologias digitais de informação e comunicação que possibilitem o desenvolvimento de objetivos de aprendizagem e habilidades previstas na BNCC, currículos e propostas pedagógicas passíveis de serem alcançados através destas práticas. Assim sendo, as atividades pedagógicas não presenciais podem acontecer por meios digitais (videoaulas, conteúdos organizados em plataformas virtuais de ensino e aprendizagem, redes sociais, correio eletrônico, blogs, entre outros); por meio de programas de televisão ou rádio; pela adoção de material didático impresso com orientações pedagógicas distribuído aos alunos e seus pais ou responsáveis; e pela orientação de leituras, projetos, pesquisas, atividades e exercícios indicados nos materiais didáticos. A comunicação é essencial neste processo, assim como a elaboração de guias de orientação das rotinas de atividades educacionais não presenciais para orientar famílias e estudantes, sob a supervisão de professores e dirigentes escolares (BRASIL, 2020d, p. 89).

As orientações permitem uma flexibilização das instituições educacionais na escolha dos recursos e é nesse contexto que destacamos os Ambientes Virtuais de Aprendizagem (AVAs). Eles são oriundos da Educação a Distância $(\mathrm{EaD})$ e têm sido utilizados por instituições educacionais de diferentes etapas e níveis na organização das turmas, das disciplinas e na interação com os estudantes. 
O uso dos AVAs sofreu adaptações no ensino remoto de emergência quando comparado a sua utilização na EaD. O motivo é justamente porque as aulas remotas não podem ser consideradas como de Educação a Distância. Isso porque compreendemos a EaD a partir da definição de Mill (2018, p. 201) o qual afirma:

De modo geral e simplificado, pode-se dizer que todos os aspectos envolvidos no ensino-aprendizagem da EaD são praticamente os mesmos da educação presencial, estruturados em um processo dialético, de modo articulado, complementar e dinâmico. Ocorre que essa base diluída e fluida da EaD se organiza em espaços e tempos redimensionamos, distintos daqueles que regiam e ainda regem a tradicional organização escolar.

Além disso, os estudos desenvolvidos no interior de um grupo de pesquisa sobre Educação a Distância e Tecnologias Educacionais, vinculado a xxxxxxx - xxxxxx/CNPq, parte das inquietações destas pesquisadoras e do esforço em produzir um material que contribua com a elucidação das condições em que nos encontramos no contexto da pandemia e na defesa de que a Educação a Distância, por meio de diversas ferramentas, metodologias, teorias e concepções pedagógicas, privilegie, de forma extensiva, a educação nas suas diferentes configurações e necessidades.

Assim sendo, este trabalho busca explorar o uso dos Ambientes Virtuais de Aprendizagem, oriundos da Educação a Distância, como importante recurso organizacional do ensino remoto de emergência. O procedimento metodológico é uma pesquisa bibliográfica e documental com abordagem qualitativa (GIL, 2008). O levantamento bibliográfico priorizará textos que abordem o tema, de forma contextualizada com o tema proposto. Os autores selecionados e seus pontos de vista encaminharam a discussão no anseio de explorar as potencialidades do uso do AVA para o atual contexto.

\section{Conceituação de educação a distância e ensino remoto de emergência}

Conceitualmente distante da Educação a Distância, o ensino remoto de emergência se caracteriza pela transposição de modelos da prática presencial para as plataformas digitais, conectadas pela internet. De toda forma, acreditamos que a consolidação da $\mathrm{EaD}$ e de seus recursos no Brasil e no mundo, contribuem para uma melhor experiência com o regime emergencial.

Portanto, para averiguarmos as contribuições da Educação a Distância para o ensino remoto de emergência em tempos de pandemia se faz necessário compreender como se 
configura cada formato. Assim sendo, apresentaremos a seguir a conceituação e as principais características de cada uma.

Amparados pela bibliografia produzida por Pimentel (2006), Moreira e Schlemmer (2020), Mill (2018), Moore e Kearsley (2013) buscamos esclarecer os conceitos que norteiam nossa pesquisa. Em seguida, analisaremos o uso dos Ambientes Virtuais de Aprendizagem, oriundos da Educação a Distância, como importante recurso organizacional do ensino remoto de emergência.

A EaD é uma modalidade de Educação em que as pessoas podem estudar em tempos e espaços diferentes. Para que isso ocorra é necessário a utilização de diferentes tecnologias de acesso que vão desde a correspondência, quando se utiliza o material impresso, até as Tecnologias da Informação e Comunicação (TICs).

Historicamente, a Educação a Distância não é uma novidade do presente século como pode parecer já que, em função da pandemia, ela tem estado bastante presente nas discussões que observamos por meio de entrevistas, textos críticos, documentos, orientações, entre outros. A EaD, no Brasil e no mundo, tem seu início no século XIX com o ensino por correspondência por meio de anúncios dos cursos em jornais. Esses cursos utilizavam os correios para o envio do material beneficiando a população com a oferta desses cursos.

Para pesquisadores como Moore e Kearsley (2013), essa foi a primeira geração da Educação a Distância. Na sequência, após o ensino por correspondência, os autores destacam o uso do rádio e da televisão como a segunda e terceira geração respectivamente. A quarta geração são as diferentes mídias proposta por Wedemeyer, nos Estados Unidos, e, por fim, a quinta geração ocorre a partir do uso dos ambientes virtuais de aprendizagem que utilizam o computador e a internet.

Permeando todas essas propostas, os estudos em EaD são acompanhados também em nível teórico. Eles ocorrem a partir de diferentes bases conceituais que discutem o conhecimento e a aquisição de informação como o construtivismo na perspectiva cognitivista, o interacionismo, o conectivismo, aprendizagem situada, entre outras. Além disso, os principais estudiosos da modalidade também desenvolveram suas teorias. De acordo com Oliveira e Costa (2018, p. 81-82):

São elas: Teoria da Industrialização de Otto Peters; Teoria da Conversação didática guiada em educação a distância de Börje Holmberg; Teoria de Estudo Independente de Charles Wedemeyer; Teoria da Distância Transacional de Michael Moore; Teoria da Reintegração dos Atos de Ensino e Aprendizagem de Desmond Keegan; Teoria da Comunicação e Controle do Aprendiz de 
Donn Randy Garrison, Terry Anderson e Walter Archer; e a Teoria da Tridimensionalidade de John Verduin e Thomas Clarck.

Dessa forma, é possível observar o quanto a modalidade exige estudos que, por consequência, exigem políticas públicas para a oferta da Educação a Distância. No Brasil, a $\mathrm{EaD}$ foi reconhecida como modalidade de ensino com a promulgação da Lei de Diretrizes e Bases da Educação Nacional n ${ }^{\circ}$ 9.394/96. Atualmente, é regulamentada pelo decreto $n^{\circ} 9.057$, de 25 de maio de 2017, que, em seu art. $1^{\text {o }}$,caracteriza a Educação a Distância como:

[...] a modalidade educacional na qual a mediação didático-pedagógica nos processos de ensino e aprendizagem ocorra com a utilização de meios e tecnologias de informação e comunicação, com pessoal qualificado, com políticas de acesso, com acompanhamento e avaliação compatíveis, entre outros, e desenvolva atividades educativas por estudantes e profissionais da educação que estejam em lugares e tempos diversos (BRASIL, 2017).

Relacionado ao contexto de pandemia, salientamos que nessa modalidade de ensino, os professores e os estudantes não estão juntos presencialmente, o que contribui para o afastamento social exigido no período de enfrentamento da Covid-19. O espaço virtual que é oriundo da Educação a Distância, por sua vez, acabou por ser o único espaço educativo possível para o momento e, portanto, é normal que as discussões atuais em relação à educação estejam voltadas a ele, observando, analisando, criticando e apontando seus limites e alcances.

Ainda sobre as características da modalidade, destacamos que, organizar um curso a partir do formato da Educação a Distância baseado em seus meios, teorias, conteúdos e metodologias, é reconhecer a importância do trabalho em equipe para assegurar seus objetivos educacionais. Esse modelo engloba diversas tarefas que, para serem executadas, precisam de uma equipe multidisciplinar para atender as necessidades da gestão à produção dos materiais didáticos (OLIVEIRA, 2018). Corroborando a ideia dessa organização essencial à modalidade, Mill (2018, p. 199) afirma que

Há mais de 30 anos, Holmberg (1985) estabeleceu algumas bases e fundamentos da $\mathrm{EaD}$, firmando seus alicerces em teorias da comunicação e da interação. Para esse autor, a expressão "educação a distância" abarca distintas formas de estudo e envolve atividades realizadas sob a supervisão (contínua ou não) de tutores/ educadores, presentes com seus alunos em sala de aula, sem dispensar os benefícios do planejamento, do acompanhamento e da orientação de uma organização tutorial pedagogicamente bem estruturada. 
Nesse sentido, observamos que a Educação a Distância envolve, além da colaboração de diferentes profissionais de design gráficos, suporte tecnológico, entre outros não ligados a diretamente a tarefa educativa, toda uma estrutura de organização e de gestão para além da simples disponibilização de materiais no Ambiente Virtual de Aprendizagem, da difusão de vídeos em plataforma do YouTube, por exemplo, ou ainda, aulas em formato de webconferência, que é unidirecional com baixa capacidade de interação.

Assim, acreditamos que, nesse contexto pandêmico em que o modelo educacional presencial migrou de forma rápida e difusa para o espaço virtual, seja necessário apresentar as principais contribuições dos Ambientes Virtuais de Aprendizagem, oriundos da Educação a Distância, para o ensino remoto de emergência.

Por fim, salientamos que, diferentemente da $\mathrm{EaD}$, que possui uma legislação específica e regulamentação para autorização, credenciamento, oferta e avaliação das instituições que atuam nesta modalidade, o ensino remoto se caracteriza pela transposição do modelo presencial para o remoto e utiliza, em muitos casos, as Tecnologias da Informação e Comunicação (TICs).

Neste período ímpar que estamos vivenciando, em que a pandemia da Covid-19 nos coloca em distanciamento social, o ensino remoto, em caráter emergencial, tem se mostrado como uma saída para que o processo de ensino e de aprendizagem escolar possa ser realizado, em todos os níveis, etapas e modalidades da educação em nosso país. Moreira e Schlemmer (2020) consideram o ensino remoto ou a aula remota como uma modalidade de ensino ou um modelo de aula que pressupõe que professores e alunos estão distantes físicamente.

Os autores ainda destacam que:

Nessa modalidade, o ensino presencial físico (mesmos cursos, currículo, metodologias e práticas pedagógicas) é transposto para os meios digitais, em rede. O processo é centrado no conteúdo, que é ministrado pelo mesmo professor da aula presencial física. Embora haja um distanciamento geográfico, privilegia-se o compartilhamento de um mesmo tempo, ou seja, a aula ocorre num tempo síncrono, seguindo princípios do ensino presencial. A comunicação é predominantemente bidirecional, do tipo um para muitos, no qual o professor protagoniza vídeo-aula ou realiza uma aula expositiva por meio de sistemas de webconferência. Dessa forma, a presença física do professor e do aluno no espaço da sala de aula geográfica são substituídas por uma presença digital numa sala de aula digital. No ensino remoto ou aula remota, o foco está nas informações e nas formas de transmissão dessas informações. A lógica que predomina é a do controle, tudo o que é concebido e disponibilizado é registrado, gravado e pode ser acessado e revisto posteriormente (MOREIRA; SCHLEMMER, 2020, p. 9). 
Assim, o ensino remoto ou aula remota visa reproduzir o exemplo realizado na modalidade presencial, com seus métodos, estratégias e didática específica utilizando como meio para a transmissão dos conteúdos aos alunos, as Tecnologias Digitais de Informação e Comunicação.

O termo "de emergência" é utilizado para designar o momento em que o ensino remoto está sendo utilizado. Isso porque ele é um modelo temporário de educação que atende as necessidades educacionais e sociais, diante de uma crise (MOREIRA; SCHLEMMER, 2020). Ou seja, é uma solução temporária até que as aulas possam retornar ao seu formato original.

Na acepção de Moreira e Schlemmer, o ensino remoto de emergência:

Envolve o uso de soluções de ensino totalmente remotas idênticas às práticas dos ambientes físicos, sendo que o objetivo principal nestas circunstâncias não é recriar um ecossistema educacional online robusto, mas sim fornecer acesso temporário e de maneira rápida durante o período de emergência ou crise (MOREIRA; SCHLEMMER, 2020, p. 9, grifos do autor).

A EaD pode ser considerada um ecossistema educacional, porém o ensino remoto de emergência, não. Após a compreensão sobre as diferenças desses dois formatos educacionais, as contribuições sobre os Ambientes Virtuais de Aprendizagem poderão ser melhor compreendidas.

Para além, salientamos que essa diferenciação é importante para não desqualificar o trabalho e o legado da Educação a Distância diante de problemas e necessidades pontuais do ensino remoto de emergência e da educação em tempos de pandemia. Isso, porque verificamos e nos preocupamos que, em muitos casos, de forma errônea, o ensino remoto de emergência tem sido utilizado como sinônimo de Educação a Distância pela sociedade.

\section{Procedimento metodológico}

O procedimento metodológico adotado neste estudo é caracterizado como uma pesquisa bibliográfica e documental, com abordagem qualitativa. A pesquisa bibliográfica e documental foi necessária para o levantamento das produções científicas e documentos legais existentes, que norteiam e embasam a temática estudada.

De acordo com Gil (2008), a pesquisa bibliográfica permite acesso especialmente a livros e artigos científicos que partem de estudos exploratórios em que a principal vantagem é compreender os estudos a partir de pesquisas existentes e consolidadas na área que nos permitem a ampliação das temáticas e das relações entre elas. 
A pesquisa documental se difere da pesquisa bibliográfica em relação a natureza das fontes. Enquanto essa recebe a contribuição de diferentes autores, aquela se dá pelo tratamento analítico das fontes originais, sem a interferência das interpretações de outros autores da área.

A análise é fundamentada em uma abordagem qualitativa que considera a fundamentação apresentada com as relações cognitivas que as pesquisadoras conseguem desenvolver (GIL, 2008), a partir de suas formações acadêmicas e experiências profissionais oriundas da educação básica e do ensino superior, frente às diversas etapas e modalidades.

\section{Primeiras reflexões: os ambientes virtuais de aprendizagem e seu uso em tempos de pandemia}

Diante da nova realidade e da incerteza constante sobre a volta às aulas presenciais, a oferta da educação precisou ser repensada. O futuro incerto sobre o processo de disseminação e controle do vírus alterou para sempre a forma de se pensar e de se fazer educação. É inegável que as experiências educacionais em tempos de pandemia causarão reflexões essenciais sobre as relações de ensino e de aprendizagem.

As instituições da educação básica e do ensino superior tiveram suas rotinas alteradas da noite para o dia. Elas, junto com seus professores, se viram obrigadas a pensar em formas alternativas e em caráter de emergência para atender seus alunos. Considerando a necessidade de realizar o isolamento social a solução mais viável e acessível foi recorrer ao uso das Tecnologias Digitais de Informação e Comunicação.

Nesse sentido, os profissionais da Educação buscaram recursos e estratégias existentes que pudessem contribuir e permitir o atendimento dos alunos, visando a garantia da oferta educacional, na tentativa de minimizar os prejuízos escolares em todos os níveis, etapas e modalidades. O suporte veio da Educação a Distância que, desde a Lei de Diretrizes e Bases da Educação Nacional no 9.394/96, é caraterizada pelo uso das Tecnologias de Informação e Comunicação e que possui uma estrutura e organização específica para ensinar os alunos em tempos e lugares diversos.

Destacamos que o ensino presencial recorreu ao uso das ferramentas da Educação a Distância para realizar o ensino remoto de emergência. Isso significa afirmar que as instituições escolares não estão ofertando $\mathrm{EaD}$, mas sim utilizando o que essa modalidade possui em nível de suporte, tal como os Ambientes Virtuais de Aprendizagem (AVAs). Porém, destacamos que as ferramentas são apenas um dos elementos que permeiam a modalidade e considerar as atuais 
ações como Educação a Distância é abrir mão de uma visão mais completa que envolve seus aspectos históricos, teóricos, metodológicos, políticos e culturais.

Considerando as discussões anteriormente realizadas, conceituando a Educação a Distância e o ensino remoto de emergência, salientamos que cada um possui suas características, assim como o ensino presencial. Nesse sentido, diante da necessidade de repensar a forma de oferta da educação em tempos de pandemia, uma das ferramentas mais utilizadas foram os AVAs.

O Ambiente Virtual de Aprendizagem se caracteriza como um espaço virtual onde atividades síncronas e assíncronas são realizadas a fim de que o processo de ensino e de aprendizagem ocorra. É uma ferramenta que possibilita que alunos e professores se encontrem e realizem atividades sistematizadas, mesmo que distante fisicamente. O AVA inclui em seu sistema diversas funcionalidades, como chats, fóruns, murais de recados, salas de bate papo, vídeo aulas, atividades de estudo, caixa de mensagens e calendário acadêmico, por exemplo.

É em torno deste ambiente de aprendizagem que o processo de ensino e de aprendizagem ocorre na Educação a Distância. Pimentel (2006) apresenta, de forma breve, algumas das ferramentas de comunicação e informação que estão disponíveis nos Ambientes Virtuais de Aprendizagem e que são utilizadas comumente por professores e alunos.

Quadro 1 - Ferramentas de informação e comunicação

\begin{tabular}{|l|c|l|}
\hline \multicolumn{1}{|c|}{ ELGEMS } & CATEGORIA & \multicolumn{1}{c|}{ DESCRIÇÃO } \\
\hline $\begin{array}{l}\text { Correio } \\
\text { Eletrônico }\end{array}$ & $\begin{array}{c}\text { Comunicação/ } \\
\text { Informação }\end{array}$ & $\begin{array}{l}\text { Indicado para enviar e receber arquivos anexados às mensagens, } \\
\text { esclarecer dúvidas, dar sugestões, etc. }\end{array}$ \\
\hline Fórum & $\begin{array}{l}\text { Comunicação/ } \\
\text { Informação }\end{array}$ & $\begin{array}{l}\text { Mecanismo propício ao desenvolvimento de debates. O fórum é } \\
\text { organizado de acordo com uma estrutura de árvore em que os } \\
\text { assuntos são dispostos hierarquicamente, mantendo a relação entre } \\
\text { o tópico lançado, respostas e contra respostas. }\end{array}$ \\
\hline Mural & Informação & $\begin{array}{l}\text { Aluno e professores podem disponibilizar mensagens que sejam } \\
\text { interessantes para todo a turma. Essas mensagens, geralmente, são: } \\
\text { divulgação de links, convites para eventos, notícias rápidas, etc. }\end{array}$ \\
\hline Perfil & Gerenciamento & $\begin{array}{l}\text { Auxilia a disponibilização de informações pessoais dos alunos e } \\
\text { professores do curso, tais como: e-mail, fotos, mini-curriculo }\end{array}$ \\
\hline
\end{tabular}




\begin{tabular}{|l|l|l|}
\hline Acompanhamento & Gerenciamento & $\begin{array}{l}\text { A ferramenta, geralmente, apresenta informações que auxiliam o } \\
\text { acompanhamento do aluno pelo professor, assim como o auto } \\
\text { acompanhamento por parte do aluno. Os relatórios gerados por essa } \\
\text { ferramenta apresentam informações relativas ao histórico de acesso } \\
\text { ao ambiente de aprendizagem pelos alunos, notas, freqüência por } \\
\text { seção do ambiente visitada pelos alunos, histórico dos artigos lidos } \\
\text { e mensagens postadas para o fórum e correio, participação em } \\
\text { sessões de chat, mapas de interação entre os professores e alunos. }\end{array}$ \\
\hline
\end{tabular}

Fonte: Pimentel (2006, p. 26), tabela adaptada.

O AVA é o espaço no qual as interações entre professores e alunos e a mediação pedagógica ocorrerão. Desta forma, é por meio das ferramentas que as trocas de informações acontecerão. Ainda há a possibilidade dos encontros presenciais, nos polos, entre tutores presenciais e os alunos, sendo este um meio de fortalecimento do processo de mediação e a criação de vínculo entre o aluno e a instituição de ensino. No entanto, na maioria das vezes, o processo de mediação acontece em sua maior parte por meio do Ambiente Virtual de Aprendizagem, tendo em vista que os alunos se encontram em regiões geográficas distantes.

No que tange à educação em tempos de pandemia, destacaremos como os Ambientes Virtuais de Aprendizagem contribuíram com as necessidades do ensino remoto de emergência. Nesse contexto, é preciso compreender que o ensino presencial é marcado pela interação síncrona que ocorre no mesmo espaço com os alunos por meio de aulas que possuem horário para iniciar e terminar.

Essa necessidade pode ser atendida pelo uso dos recursos de webconferência em que todos estão sincronamente conectados pelos recursos tecnológicos,àcom acesso à internet, porém separados fisicamente. De forma geral, as instituições educacionais organizaram suas aulas virtuais para que ocorressem no mesmo tempo destinado as aulas que deveriam ser presenciais, respeitando assim a organização letiva pré-estabelecida no início do ano.

Para além dessa interação entre professores e alunos, era necessário se pensar como organizar a aula de forma que os alunos pudessem encontrar as orientações, os materiais, as atividades e os recados das aulas. É nesse contexto que os Ambientes Virtuais de Aprendizagem se mostraram eficientes para as instituições de educação básica e ensino superior.

Eles foram utilizados respeitando a ideia de flexibilização explícita no parecer CNE/CP $n^{\circ} 5 / 2020$, de 28 de abril de 2020, quando são respeitadas as especificidades e necessidades de cada instituição educacional, bem como de seus professores e alunos. Isso significa que nem todos os recursos do Ambientes Virtuais de Aprendizagem foram utilizados igualmente por 
todas as instituições, o que demonstra mais uma vez que não está sendo feita Educação a Distância, mas sim utilizando parcialmente algumas de suas ferramentas para assegurar o atendimento pedagógico e a continuidade da formação dos estudantes brasileiros nas mais diversas etapas, níveis e modalidades.

Os Ambientes Virtuais de Aprendizagem, no ensino remoto de emergência, permitiram aos professores organizarem as disciplinas e as aulas em um espaço específico de fácil acesso. Para os responsáveis dos alunos que estavam em casa supervisionando e dando suporte para eles, tal ambiente facilitou o acompanhamento diário das aulas e das atividades, justamente por permitir uma organização mais clara de como as aulas seriam realizadas dia após dia.

Não podemos desconsiderar que os professores responsáveis por ministrar essas aulas também estavam em processo de readaptação da rotina familiar e de suas ocupações profissionais. A demanda de atenção que as crianças da educação infantil até o ensino fundamental anos iniciais exigem no seu processo aprendizagem necessita de uma rotina, organização e suporte pedagógico que foram prejudicados no período de isolamento e que necessitaram de total apoio dos responsáveis para que fossem garantidos.

Nesse sentido, os Ambientes Virtuais de Aprendizagem foram ferramentas que contribuíram com a organização de professores e dos responsáveis diante da nova organização social e educacional permitindo uma maior adequação junto as outras demandas de cada família como, por exemplo, o trabalho em formato home office, também utilizado no período de isolamento social como uma estratégia do mercado de trabalho para manter seu funcionamento.

Por isso, os Ambientes Virtuais de Aprendizagem se fizeram essenciais nesse processo de organização para que os prejuízos educacionais fossem minimizados. Quanto mais organizado e simplificado, mais fácil era para alunos e familiares acompanharem as aulas e discussões. De forma geral, a sala de aula presencial foi transposta para a virtual.

Porém o aspecto essencial que a Educação a Distância nos traz é transformar os Ambientes Virtuais de Aprendizagem em espaços de interação pedagógica, em que são pensados para promover a troca de saberes entre professores e alunos. Essa interatividade expressa a dinâmica dos AVAs na promoção do conhecimento, do contrário é somente um espaço de repositório de materiais, proposta essa incompatível com as contribuições da EaD.

Um recurso utilizado com frequência no Ambientes Virtuais de Aprendizagem foram os Fóruns de discussões que permitiram professores e alunos ampliarem a compreensão dos conteúdos de forma síncrona ou assíncrona. Ao ficar registrado tornou um elemento de consulta 
possibilitando a retomada sempre que necessário para esclarecimentos de dúvidas ou acompanhamento pedagógico.

É característico dos Fóruns de discussão um posicionamento e uma participação mais ativos dos estudantes decorrentes da interação ser especificamente pela escrita. Nesse sentido, os estudantes são tirados da sua zona de conforto quando comparados a ensino presencial. Esse tipo de interação exige dos envolvidos um domínio do código formal da escrita e sua articulação com as interpretações e relações com o conteúdo que precisam ser expressas de forma clara e objetiva pela escrita permitindo que a mensagem correta chegue aos leitores desses enunciados.

$\mathrm{Na}$ dinâmica do ensino presencial é possível que os professores realizem a leitura corporal de seus alunos para ajudar a identificar se estão ou não compreendo o conteúdo, especialmente para aqueles que não costumam participar ativamente por meio da fala. Todavia, essa leitura corporal não é possível de ser realizada nos Ambientes Virtuais de Aprendizagem, por isso a importância da participação dos estudantes, para que o professor consiga acompanhar o processo de aprendizagem dos alunos e organizar sua proposta de mediação pedagógica e tecnológica, visando assegurar a continuidade da aprendizagem dos estudantes.

Outro recurso importante dos Ambientes Virtuais Aprendizagem foi o mural como espaço de recados, facilitando a comunicação entre professores, alunos e responsáveis. As pastas e os links de acesso às atividades reforçaram a organização e permitiram aos alunos encontrá-los com mais facilidade. Os materiais disponibilizados para as aulas garantiram que todos tivessem acesso ao texto correto, evitando que os alunos perdessem tempo ou a aula do dia.

Existem diversos tipos de Ambientes Virtuais de Aprendizagem e algumas instituições de ensino utilizava-os, anteriormente à pandemia, como uma ferramenta extraclasse em que alunos usavam com frequência para realização de atividades, nos mais diversos formatos online, especialmente no ensino fundamental anos finais e ensino médio das instituições particulares.

Esses Ambientes faziam parte do sistema de ensino adquirido pelas instituições e, com a readaptação das aulas para o ensino remoto de emergência, passaram a ser bem mais utilizados. No ensino superior, as instituições que ofertavam a Educação a Distância possuíam um Ambiente Virtual de Aprendizagem, que foi disponibilizado também para os cursos do ensino presencial.

Para além disso, algumas instituições públicas e privadas, de forma geral, que não ofertam cursos na modalidade a distância ou não possuíam um Ambiente Virtual de 
Aprendizagem aderiram ao uso de Ambientes gratuitos e de fácil acesso pelas plataformas digitais disponibilizados no mercado.

Destacamos que as instituições conseguiram readaptar a oferta da Educação, em decorrência das possibilidades oriundas do uso das Tecnologias Digitais de Informação e Comunicação nas suas diversas etapas, níveis e modalidades de ensino. De forma especial, os Ambientes Virtuais de Aprendizagem permitiram a organização da sala de aula virtual em que alunos puderam encontrar os encaminhamentos pedagógicos, os materiais, as atividades e os recados sobre as disciplinas garantindo assim a continuidade do atendimento educacional sem perder a interatividade pedagógica com os colegas e professores assim como no ensino presencial.

\section{Conclusões}

Diante das discussões apresentadas, concluímos que a educação pós-pandemia sofrerá significativas mudanças, no que tange a maneira de pensá-la e ofertá-la diante do uso das Tecnologias de Informação e Comunicação.

Também pudemos concluir que a Educação a Distância embasada em todo conhecimento elaborado na área possibilitou que o ensino presencial continuasse a atender os alunos durante o isolamento social por meio do uso de algumas de suas ferramentas no formato de ensino remoto de emergência.

É inegável que a EaD contribuiu com esse processo de readaptação permitindo que suas ferramentas fossem direcionadas para um atendimento emergencial em todo o mundo. Esse tipo de ensino é a transposição das aulas presenciais para as virtuais por meio do uso das Tecnologias de Informação e Comunicação em tempos de pandemia.

Destacamos especialmente os Ambientes Virtuais de Aprendizagem que permitiram a organização das disciplinas e dos encaminhamentos pedagógicos, garantindo acesso aos materiais da disciplina, aos recados, as atividades e aos fóruns de discussão do conteúdo. Os AVAs se destacaram pela capacidade de organização e disponibilização de materiais para as aulas virtuais, permitindo facilidade de acesso e acompanhamento pelos alunos e seus responsáveis quando em idade escolar.

Porém, o aspecto essencial de contribuição da Educação a Distância é o uso dos Ambientes Virtuais de Aprendizagem promovendo a interatividade entre professores e alunos no processo de ensino e de aprendizagem. A interação pedagógica síncrona ou assíncrona possibilita diversas experiências que contribuem com a aprendizagem dos alunos. 


\section{Referências}

BRASIL. Ministério da Educação. Lei no 9.057, de 25 de maio de 2017. Regulamenta o art. 80 da Lei $\mathrm{n}^{\circ}$ 9.394, de 20 de dezembro de 1996, que estabelece as diretrizes e bases da educação nacional.

BRASIL. Lei $\mathbf{n}^{0}$ 13.979, de 6 de fevereiro de 2020. Dispõe sobre as medidas para enfrentamento da emergência de saúde pública de importância internacional decorrente do Coronavírus responsável pelo surto de 2019. 2020a. Disponível em: http://www.planalto.gov.br/ccivil_03/_ato2019-2022/2020/lei/L13979.htm Acesso em: 30 maio 2020.

BRASIL. Ministério da Educação. Portaria no 343, de 17 de março de 2020. Dispõe sobre a substituição das aulas presenciais por aulas em meios digitais enquanto durar a situação de pandemia do Novo Coronavírus - COVID-19. 2020b. Disponível em: http://www.in.gov.br/en/web/dou/-/portaria-n-343-de-17-de-marco-de-2020-248564376. Acesso em: 30 maio 2020.

BRASIL. Ministério da Educação. Portaria no 345, de 19 de março de 2020. Dispõe sobre a substituição das aulas presenciais por aulas em meios digitais enquanto durar a situação de pandemia do Novo Coronavírus - COVID-19. 2020c. Disponível em:

https://abmes.org.br/arquivos/legislacoes/Portaria-mec-345-2020-03-19.pdf. Acesso em: 30 maio 2020.

BRASIL. Conselho Pleno. Conselho Nacional de Educação. Parecer CNE/CP n ${ }^{0}$ 5/2020, de 28 de abril de 2020. Reorganização do Calendário Escolar e da possibilidade de cômputo de atividades não presenciais para fins de cumprimento da carga horária mínima anual, em razão da Pandemia da COVID-19. 2020d. Disponível em:

$<$ http://portal.mec.gov.br/index.php?option=com_docman\&view=download\&alias $=145011$ pcp005-20\&category_slug=marco-2020-pdf\&Itemid=30192>. Acesso em: 30 maio 2020.

GIL, A. C. Como elaborar projetos de pesquisa. 4. ed. São Paulo: Atlas, 2008.

MILL, D. Educação a Distância. In: MILL, D. (org.). Dicionário Crítico de Educação e Tecnologias e de Educação a Distância. Campinas, SP: Papirus, 2018. p. 198-203.

MINAYO, M. C. de S. (org.). Pesquisa Social. Teoria, método e criatividade. 18. ed. Petrópolis: Vozes, 2001.

MOORE, M.; KEARSLEY, G. Educação a distância: sistemas de aprendizagem on-line. 3. ed. São Paulo: Cengage Learning, 2013.

MOREIRA, A. J., SCHLEMMER, E. Por um novo conceito e paradigma de educação digital onlife. Revista UFG, Goiania, v. 20, jan. 2020. Disponível em:

$<$ https://www.revistas.ufg.br/revistaufg/article/view/63438>. Acesso em: 13 jun. 2020. 
OLIVEIRA, P. L. L. M. Pesquisas em educação musical a distância no Brasil:

mapeamento de teses e dissertações (2002 - 2015). 230f. Tese (Doutorado em Educação) Universidade Estadual de Maringá. Orientadora: Maria Luisa Furlan Costa. Maringá, 2018.

OLIVEIRA, P. M. G. de; COSTA, M. L. F. Mapeamento da pesquisa em Educação Musical a Distância no Brasil. Curitiba, PR: Editora CRV, 2018.

PIMENTEL, N. M. Introdução à educação à distância. Florianópolis: SEAD/UFSC, 2006. 